\title{
Laboratory Evaluation of Select Methods of Corrosion Prevention in Reinforced Concrete Bridges
}

\author{
Matthew D. Pritzl ${ }^{1)}$, Habib Tabatabai ${ }^{2), *}$, and Al Ghorbanpoor ${ }^{2)}$
}

(Received October 5, 2013, Accepted April 11, 2014)

\begin{abstract}
Sixteen reinforced concrete laboratory specimens were used to evaluate a number of corrosion prevention methods under an accelerated (6 months) testing program. The use of galvanic thermal sprayed zinc, galvanic embedded anodes, a tri-silane sealer, an acrylic coating, and an epoxy/polyurethane coating was evaluated. The specimens received various treatments prior to exposure to accelerated corrosion. The performance of the treatments was evaluated with respect to corrosion currents, chloride ingress, extent of cracking, severity of rust staining, and visual inspection of the reinforcing steel after the conclusion of testing and dissection. Results indicated that the tri-silane sealer, the conjoint use of galvanic thermal sprayed zinc and epoxy/polyurethane coating, the epoxy/polyurethane coating, and acrylic coating performed better than the other methods tested. Higher chloride concentrations were measured in the vicinity of embedded zinc anodes.
\end{abstract}

Keywords: corrosion, coatings, sealers, corrosion inhibitors, sacrificial cathodic protection, chloride ingress.

\section{Introduction}

Reinforced concrete bridge maintenance and repair is a costly national concern. In northern states, the ingress of chlorides from deicing salts continues to cause considerable deterioration that requires periodic maintenance and expensive repair (Federal Highway Administration 1998; Emmons 1993; El-Reedy 2008). Corrosion of the reinforcing steel in concrete can lead to cracking, delamination, and spalling of concrete. When significant cracking, delamination and spalling occur, repairs need to be undertaken. To reduce the need for repairs, several methods have been introduced to prevent the initiation and progression of corrosion damage.

In this study, the use of galvanic thermal sprayed zinc (TSZ), galvanic embedded anodes (EA), a tri-silane sealer (T-SS), an acrylic coating (AC), and an epoxy/polyurethane coating (EP-C) was evaluated experimentally. The choice of the corrosion prevention (CoP) measures to be evaluated was made by the project sponsor. Sixteen reinforced concrete laboratory specimens were used to evaluate a number of CoP methods under an accelerated (6 month) testing program. The specimens received various treatments prior to exposure to accelerated corrosion.

\footnotetext{
${ }^{1)}$ Donan Engineering Co., Inc., Louisville, KY 40299, USA.

${ }^{2)}$ Department of Civil and Environmental Engineering, University of Wisconsin-Milwaukee, Milwaukee WI 53211, USA.

*Corresponding Author; E-mail: ht@uwm.edu Copyright ( $\odot$ The Author(s) 2014. This article is published with open access at Springerlink.com
}

\section{Research Background}

Corrosion prevention methods can be divided into electrical and non-electrical. Non-electrical methods include coatings, sealers, and corrosion inhibiting admixtures. Cathodic protection is an electrical approach that can be used to prevent corrosion by shifting the reinforcing steel into a protected state.

\subsection{Coatings and Sealers}

The application of protective sealers and coatings on the concrete surface helps prevent the initiation of corrosion and increases life expectancy when employed before chloride contamination of the concrete (Ball and Whitmore 2003). Tabatabai et al. found that surface treatments (coatings) applied to the end zones of precast/prestressed concrete bridge girders at the time of construction can successfully prevent beam end corrosion (Tabatabai et al. 2005).

Epoxy-coated reinforcing bars have long been used as a protective measure in reinforced concrete applications. However, the use of epoxy-coated bars is not included in this study. The use of selected coatings and sealers on the concrete surface is included in the experimental work reported here.

\subsection{Corrosion Inhibiting Admixtures}

Corrosion inhibiting admixtures, which are added to the concrete at the time of mixing, are used to delay the onset of corrosion in reinforced concrete. The inhibitors work by either slowing the ingress of aggressive ions, such as chlorides, or increasing the amount of chlorides necessary to initiate the corrosion process (Brown 1999). The use of corrosion inhibiting admixtures is not included in the study reported here. 


\subsection{Cathodic Protection}

Discrete (embedded) anode galvanic cathodic protection systems are intended to provide localized protection to the reinforcing steel adjacent to the anode. The anode is intended to be consumed in preference to the reinforcing steel, thus protecting it (Ball and Whitmore 2003). The discrete anodes are typically attached directly to the reinforcing steel through wire ties. Two types of embedded discrete anodes are included in the experimental work reported here.

\subsection{Metalizing}

Metalizing, or thermal spraying, is a method where a molten metal is sprayed onto a prepared substrate. A connection is then made between the embedded reinforcing steel and the sprayed metal. For reinforced concrete structures, the most commonly used thermal sprayed anodes are pure zinc and a proprietary aluminum-zinc-indium alloy (Al-Zn-In). The sprayed metal is consumed in preference to the embedded reinforcing steel.

Environmental conditions will affect the levels of cathodic protection and current densities achieved with thermal sprayed metals. Moisture content at the anode/concrete interface and temperature are environmental conditions that affect the current output (Daily and Green 2005). In high resistivity environments (i.e., dry environments), the $\mathrm{Al}-\mathrm{Zn}-$ In alloy will deliver more current than pure zinc because the indium keeps the anode more active (Daily and Green 2005). However, a humectant can be added to pure zinc to increase moisture content at the zinc-concrete interface, thereby reducing the resistivity and increasing current output (Holcomb et al. 2002). The use of zinc spray coating on the concrete surface is included in this study.

\section{Experimental Investigation}

Based on the results of an in-depth literature review, the following CoP methods were selected for evaluation in this experimental work: two (2) types of embedded galvanic anodes, a humectant activated galvanic thermal sprayed zinc, a penetrating T-SS, an EP-C, and an acrylic coating. The EP$\mathrm{C}$ included a first coating of epoxy followed by a second coating of polyurethane.

\subsection{Accelerated Corrosion Method}

To gauge the long-term corrosion performance of reinforcing steel in concrete in a relatively short time period (duration of research), it is necessary to employ accelerated corrosion techniques. General accelerated deterioration techniques for metals and coatings (such as salt fog testing) have long been used in product testing and research. A number of researchers have used an impressed current accelerated corrosion technique combined with salt water exposure for evaluation of long-term chloride-induced corrosion in reinforced concrete. Examples include works by Ray et al. (2011), Mullard and Stewart (2011), Michel et al. (2011), Abosrra et al. (2011), El Maaddawy and Soudki (2003), and Austin et al. (2004).

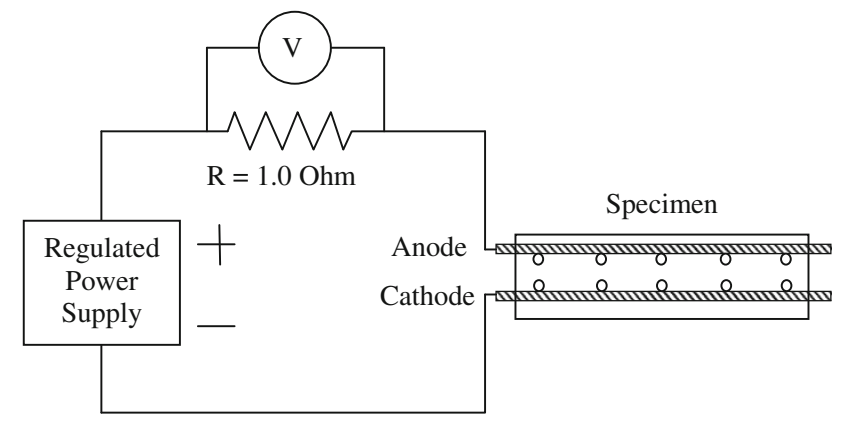

Fig. 1 Corrosion cell for laboratory specimens.

In this research, accelerated corrosion testing was accomplished by subjecting the test specimens to cycles of 1 week wet, using a $6 \% \mathrm{NaCl}$ solution ponded on top of the specimens, and 1 week dry. In addition, a reverse cathodic protection system was created by continuously applying a regulated voltage of $9 \mathrm{~V}$ between the top layer of reinforcement (the anode) and the bottom layer (the cathode) to accelerate the corrosion process. Corrosion currents were measured across a $1 \Omega$ precision resistor (Fig. 1). The initial measured current density on the anode bars (corresponding to $9 \mathrm{~V}$ ) was on the order of $30-45 \mu \mathrm{A} / \mathrm{cm}^{2}$.

The treatments in question were evaluated with respect to corrosion currents, chloride ingress, half-cell potential readings, extent of cracking, severity of rust staining, and visual inspection of the reinforcing steel after the conclusion of testing and dissection.

\subsection{Specimens and Materials}

Sixteen reinforced concrete test specimens were cast (Fig. 2). Ready-mixed air-entrained concrete was used to fabricate the test specimens. Concrete mix proportions were as follows: portland cement at $450 \mathrm{lb}(204 \mathrm{~kg})$; Class C fly ash at $100 \mathrm{lb}(45 \mathrm{~kg})$; fine aggregate at 1,370 lb (621 kg); and coarse aggregate at $1,830 \mathrm{lb}(830 \mathrm{~kg})$. The minimum specified 28th day concrete compressive strength was 4,000 psi $(27.6 \mathrm{MPa})$. Curing consisted of covering the specimens with plastic sheathing for 7 days. Note that the actual measured 28-day compressive strength was 5,839 psi (40.3 MPa), based on an average of three cylinders.

The reinforced concrete test specimens had dimensions of 28 in. $(71.1 \mathrm{~cm}) \times 28$ in. $(71.1 \mathrm{~cm}) \times 8$ in. $(20.3 \mathrm{~cm})$. No. 5 reinforcing bars (diameter of $5 / 8$ in. or $15.9 \mathrm{~mm}$ ) meeting the requirements of ASTM A615M were used.

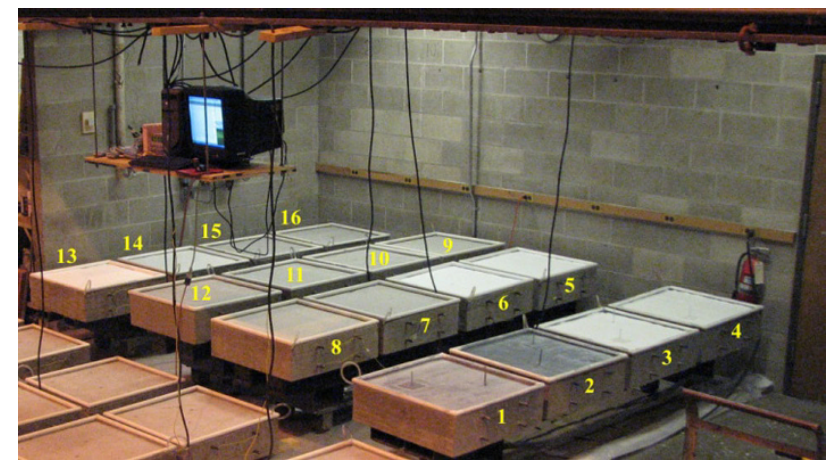

Fig. 2 Experimental setup. 


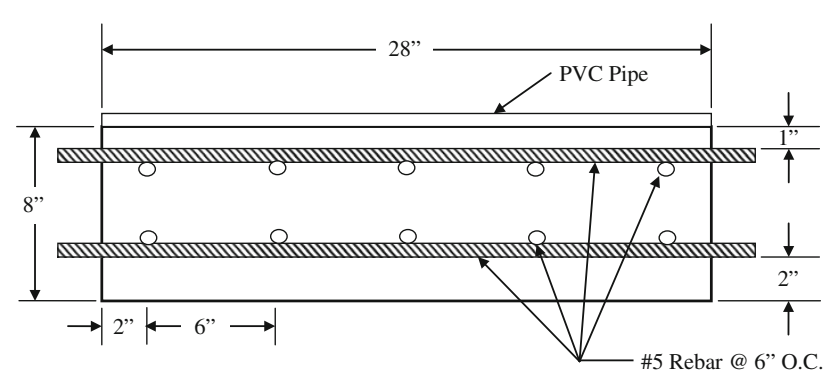

Fig. 3 Cross section of concrete specimens ( $1 \mathrm{in} .=25.4 \mathrm{~mm}$ ).

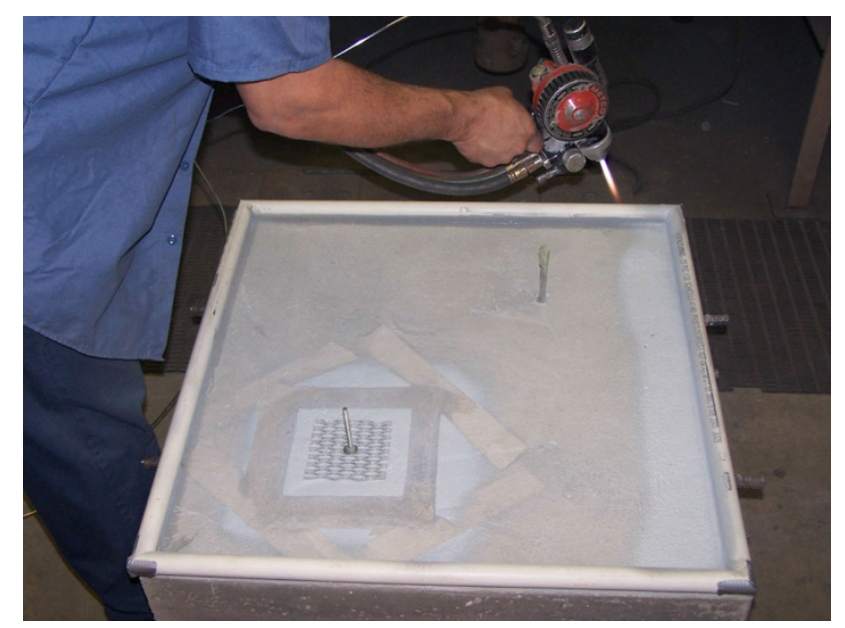

Fig. 4 Application of thermal sprayed zinc.

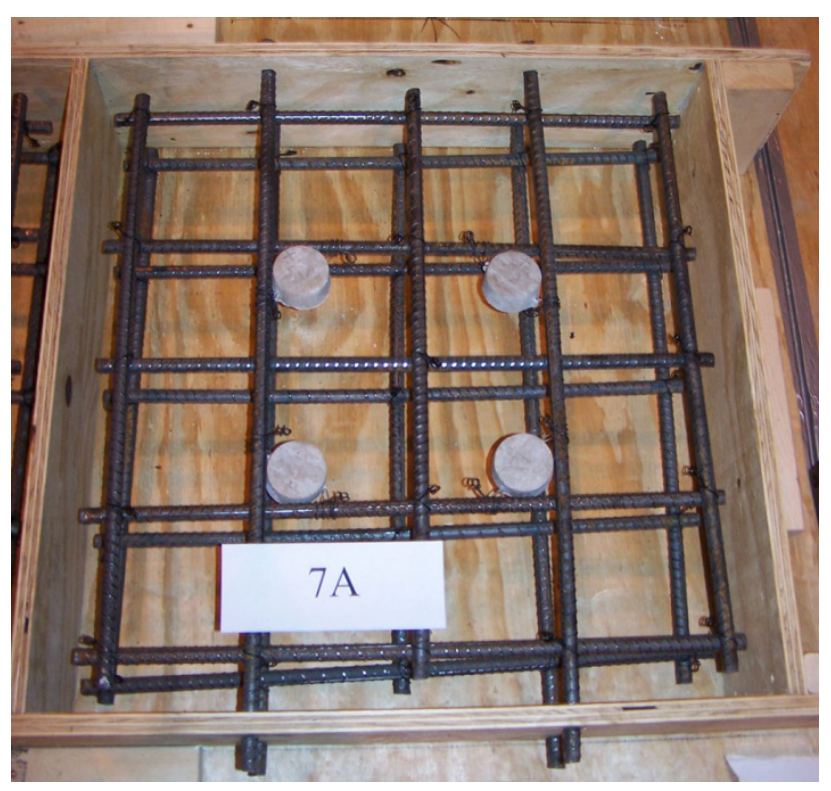

Fig. 5 Placement of embedded galvanic anodes.

To reduce the length of time needed for chlorides to reach the top steel layer, the top layer of reinforcement utilized a 1 in. $(2.5 \mathrm{~cm})$ clear cover. A 2 in. $(5.1 \mathrm{~cm})$ clear cover was used for the bottom layer of reinforcement. PVC pipe was caulked to the perimeter of the top surface of the concrete specimens to create the reservoir that periodically held the salt laden water (Fig. 3). All surface treatments were added after the PVC pipe was in place.
The application of the thermal sprayed zinc and location of the embedded galvanic anodes is depicted in Figs. 4 and 5, respectively. The description of the treatment(s) used on each specimen is shown in Table 1.

\subsection{Measurements}

Over the duration of testing, corrosion currents were measured on a daily basis. The measured corrosion currents were then integrated to estimate the relative magnitude of steel loss due to corrosion. The amount of steel loss can be estimated using Faraday's Law (Tabatabai et al. 2005).

$$
m=\frac{A^{t m} C}{F z}
$$

$M$ is the loss of mass, $A^{t m}$ is the atomic mass of the reaction ion ( $55.85 \mathrm{~g} / \mathrm{mol}$ for iron), $C$ is the total charge that has passed through the circuit $=\int I(t) d t, I(t)$ is the measured corrosion current at time $(t), F$ is the Faraday's constant $(96,485 \mathrm{C} / \mathrm{mol})$, $Z$ is the valence of reaction (assumed to be 2 ).

The chloride content of all specimens was determined by analyzing drilled concrete samples at various depths using the Rapid chloride test (RCT) method (Germann Instruments 2006). The RCT method measures the acid soluble chlorides as a percentage of concrete mass. The base-line chlorides for the specimens were determined prior to exposure.

After 6-months of accelerated testing, the chloride contents of the 16 specimens were evaluated at depths of $1 / 4$ in. $(0.64 \mathrm{~cm}), \quad 1 / 2$ in. $(1.27 \mathrm{~cm}), 3 / 4$ in. $(1.91 \mathrm{~cm}), 1 \mathrm{in}$. $(2.54 \mathrm{~cm}), 1-1 / 4$ in. $(3.18 \mathrm{~cm}), 1-1 / 2$ in. $(3.81 \mathrm{~cm}), 1-3 / 4 \mathrm{in}$. $(4.45 \mathrm{~cm})$, and $2 \mathrm{in} .(5.08 \mathrm{~cm})$. Three locations, for a total of 24 chloride tests, were analyzed per specimen. Thus, each reported value of chlorides in this paper is based on the average of three separate concrete powders. These arbitrary locations selected for testing were consistent in each specimen tested (Fig. 6). Note that Locations A, B, and C were part of a companion study.

A regression analysis was performed to further analyze the chloride content results and provide a direct comparison among the specimens. The analysis involved finding the parameters for Fick's 2nd Law of Diffusion (Eq. (2)) using optimization and regression analyses so that they best-fit the experimental data (Weyers 1994). This optimization effort utilized Microsoft Excel's "solver" function and involved minimizing the sum of squares of errors between measured and estimated chloride concentrations.

$$
C_{(x, t)}=C_{0}\left(1-\operatorname{erf} \frac{x}{2 \sqrt{D t}}\right)
$$

$C(x, t)$ is the chloride concentration at depth $x$ and time $t, C_{0}$ is the surface chloride diffusion $\left(\mathrm{lb} / \mathrm{yd}^{3}\right.$ or $\left.\mathrm{kg} / \mathrm{m}^{3}\right)$, erf is the error function (a mathematical function), $D$ is the chloride diffusion coefficient $\left(\mathrm{in}^{2} /\right.$ year or $\mathrm{cm}^{2} /$ year).

The results of the various measurements (to be discussed) were given numerical indices (Eq. (3)) according to a scale 
Table 1 Table of products used and application to which specimens.

\begin{tabular}{|c|c|c|c|}
\hline Specimen \# & Type of treatment & General description & Notation \\
\hline 01 and 02 & Thermal sprayed galvanic anode & $\begin{array}{l}\text { Humectant activated thermal } \\
\text { sprayed zinc }\end{array}$ & TSZ \\
\hline 03 and 04 & $\begin{array}{c}\text { Thermal sprayed galvanic anode } \\
\text { with coating }\end{array}$ & $\begin{array}{l}\text { Humectant activated thermal } \\
\text { sprayed zinc with epoxy/ } \\
\text { polyurethane coating }\end{array}$ & TSZ w/EP-C \\
\hline 05 and 06 & $\begin{array}{l}\text { Embedded galvanic anode with } \\
\text { coating }\end{array}$ & $\begin{array}{c}\text { Cylindrical-shaped zinc anode with } \\
\text { acrylic coating }\end{array}$ & EA-A w/A-C \\
\hline 07 and 08 & Embedded galvanic anode & Cylindrical-shaped zinc anode & EA-A \\
\hline 09 and 10 & Embedded galvanic anode & Box-shaped zinc anode & EA-B \\
\hline 11 and 12 & Penetrating sealer & Alkylalkoxysilane (tri-silane) & T-SS \\
\hline 13 & Coating & Acrylic coating & $\mathrm{A}-\mathrm{C}$ \\
\hline 14 & Coating & Epoxy/polyurethane coating & EP-C \\
\hline 15 and 16 & Control & No treatment & Control \\
\hline
\end{tabular}

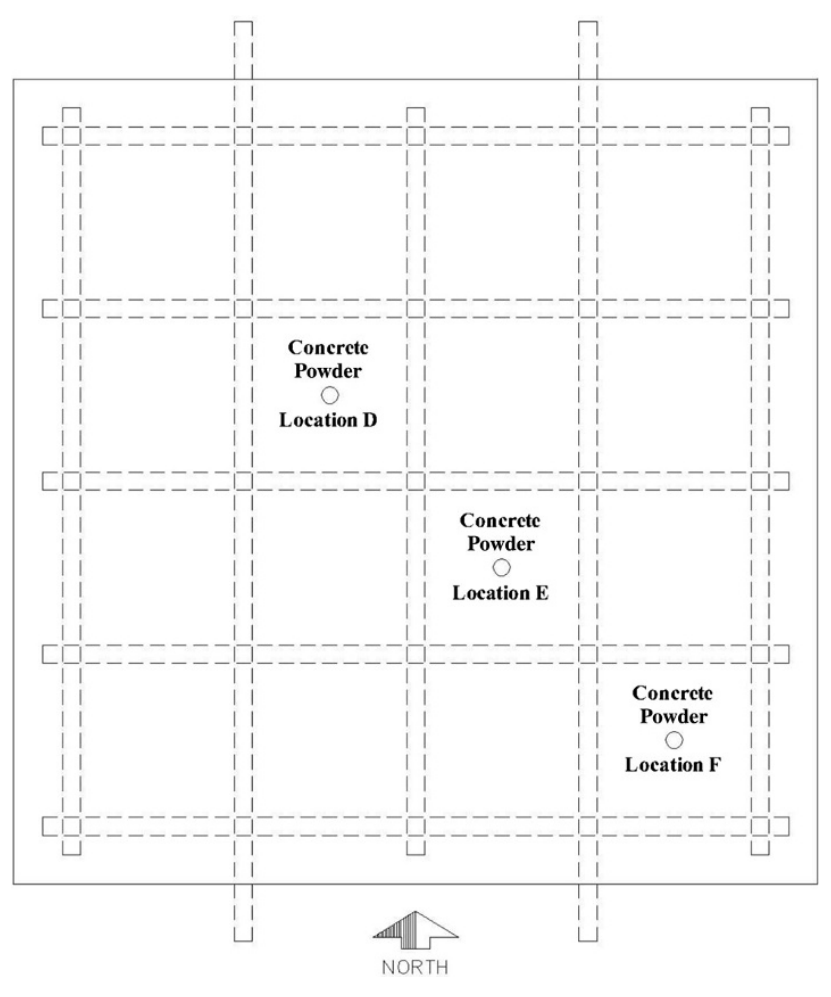

Fig. 6 Locations selected for concrete powders.

of 0 (minimum) to 4 (maximum). The actual value is the value associated with the parameter of interest for each specimen, while the minimum and maximum values used in Eq. (3) are based on the minimum and maximum values observed across all specimens. For example, the minimum and maximum steel loss values across all specimens corresponded to ratings of 0 and 4 , respectively.

$$
\text { Index }=\left(\frac{(\text { actual value })-(\text { minimum value })}{(\text { maximum value })-(\text { minimum value })}\right) \times 4
$$

Periodically, half-cell potential readings were taken. The readings were taken at sixteen locations per specimen; however, the readings were only taken on specimens that did not contain coatings. Detailed crack-maps were generated at 0,3 , and 6-month exposure. The widths of the cracks were measured using a standard crack width comparator.

At the conclusion of testing, the extent of rust-staining on the concrete surface was evaluated. Finally, the specimens were dissected and the embedded reinforcing steel was visually evaluated for extent of corrosion.

\section{Experimental Results}

A detailed report of this experimental program and its individual results are provided by Tabatabai et al. (2009). In the following discussion, the average results are shown for brevity. Individual results for companion specimens used in averaging were in reasonable agreement.

\subsection{Corrosion Currents}

Plots of average corrosion current versus time for the specimens are shown in Fig. 7. Each line represents average results from two identical specimens, except for Specimens 13 and 14. For uncoated specimens, the corrosion currents generally increased during the wet periods (shaded region) and decreased during the dry periods.

From the initiation of testing until approximately 60 days, all specimens appeared to exhibit a decrease in measured corrosion currents. Tabatabai et al. reported that this phenomenon is common in such experiments as the corrosion products increase the electrical resistance around the bar, thereby decreasing current when a fixed voltage is applied (Tabatabai et al. 2005).

After 60 days, the T-SS, EP-C, TSZ w/EP-C, A-C, TSZ, and $\mathrm{EA}-\mathrm{A}$ w/A-C specimens continued to display a decrease in corrosion current with respect to time. Meanwhile, the corrosion currents for the EA-A and Control specimens remained relatively constant. However, the EA-B specimens 


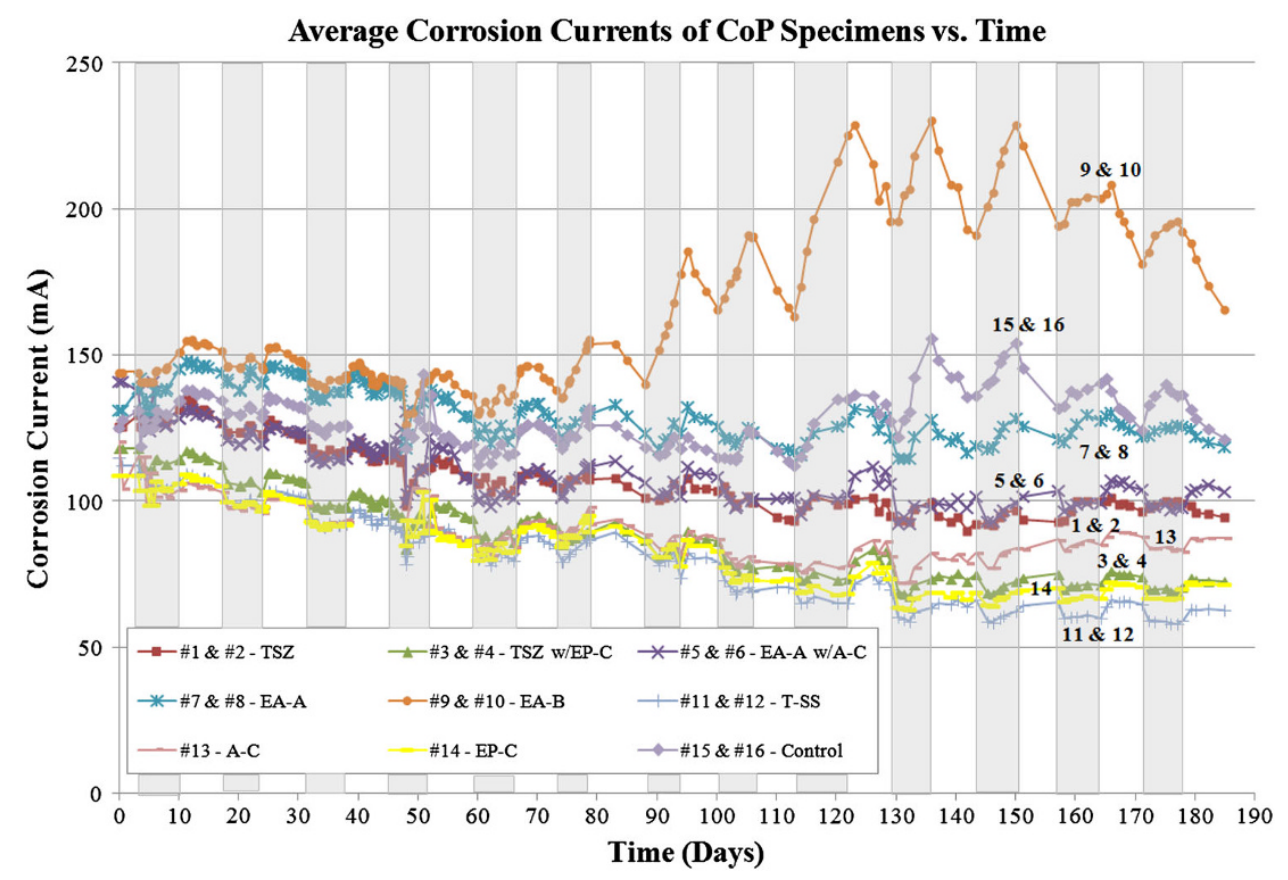

Fig. 7 Average corrosion currents of CoP specimens.

displayed an increase in current. Chloride testing (discussed later) showed that a non-uniform chloride profile developed in the horizontal plane, with higher levels exhibited in the vicinity of the anodes. This is believed to have created more pronounced anodic and cathodic zones on the rebar and thus increased the corrosion current. The negatively charged chloride ions are expected to be attracted to the vicinity of the positively charged zinc anodes.

When comparing the conjoint use of coatings with galvanic anodes (whether they be embedded or thermal sprayed), it was found that the coatings helped reduce corrosion currents. Coated systems limit chloride penetration and can lead to drier concrete (higher resistance). While the corrosion currents for the EP-C and TSZ w/EP-C were similar, the specimens with TSZ alone exhibited higher corrosion currents. In regards to the use of coatings with or without embedded anodes, the acrylic coating (A-C) alone exhibited a lower corrosion current than the EA-A w/A-C. However, specimens with the EA-A alone exhibited higher corrosion currents than that of the specimens with EA-A w/A-C.

Based on the results of the current monitoring for the laboratory specimens, it can be concluded that the T-SS, EP$\mathrm{C}$, and thermal sprayed zinc with epoxy/polyurethane coating (TSZ w/EP-C) were most effective in preventing or mitigating corrosion activity.

\subsection{Steel Loss}

By utilizing the aforementioned corrosion currents, the theoretical amount of steel loss was estimated and compared (Table 2). Based on the results of Table 2, the T-SS, EP-C, TSZ w/EP-C and A-C specimens produced the lowest theoretical steel loss indices. In contrast, the EA-B, EA-A, and Control specimens had the highest indices. When comparing these average theoretical steel loss indices to the corrosion currents of Fig. 6, a direct relationship can be seen.

\subsection{Chloride Ingress}

The baseline chloride content was taken at two locations in three separate specimens prior to accelerated corrosion exposure. At each location, samples were taken at two different depths from the concrete surface. The samples were taken from depths of $0-1 / 2$ in. $(0-1.27 \mathrm{~cm})$ and $1 / 2-1$ in. $(1.27-2.54 \mathrm{~cm})$.

The average measured chloride content of the virgin concrete was found to be $0.042 \%$ by concrete weight, or approximately $1.65 \mathrm{lb} / \mathrm{yd}^{3}\left(0.98 \mathrm{~kg} / \mathrm{m}^{3}\right)$ of concrete. This measured chloride content was considered to be relatively high. Using a 1:6 cement to concrete ratio, the base-line chloride content was $0.252 \%$ by weight of cement, which is approximately 2.5 times greater than the acid-soluble limit recommended by ACI 222 (American Concrete Institute Committee 222 2001). Similarly high chloride levels were observed, and tests were conducted to find the source in an earlier study conducted by Tabatabai et al. (2005). It was determined that coarse aggregates (limestone) were the source of the high chloride levels found in the virgin concrete. It was not clear from the tests performed whether the acid-soluble chlorides measured were bound within the aggregates, or if they could enter the cement paste (Tabatabai et al. 2005).

Chloride analyses were performed after the completion of 6-months of accelerated testing. Specimens No. 7 (Location E), No. 9 (Locations D and E), and No. 10 (Location D) produced chloride profiles that were not consistent with the classic Fick's 2nd Law of Diffusion (Fig. 8). Because of these inconsistent values, 2-4 additional locations were tested near each area in question. 
Table 2 Average steel loss of specimens after 6 months of exposure.

\begin{tabular}{c|c|c|c}
\hline Specimen $\#$ & Treatment & Average theoretical steel loss $(\mathrm{g})$ & Index (0-4) \\
\hline \hline 1 and 2 & TSZ & 492.0 & 1.1 \\
\hline 3 and 4 & TSZ w/EP-C & 402.0 & 0.3 \\
\hline 5 and 6 & EA-A w/A-C & 503.4 & 1.2 \\
\hline 7 and 8 & EA-A & 596.0 & 1.9 \\
\hline 9 and 10 & EA-B & 787.1 & 3.6 \\
\hline 11 and 12 & T-SS & 367.6 & 0.0 \\
\hline 13 & A-C & 420.5 & 0.5 \\
\hline 14 & EP-C & 396.1 & 0.3 \\
\hline 15 and 16 & Control & 593.3 & 1.9 \\
\hline
\end{tabular}

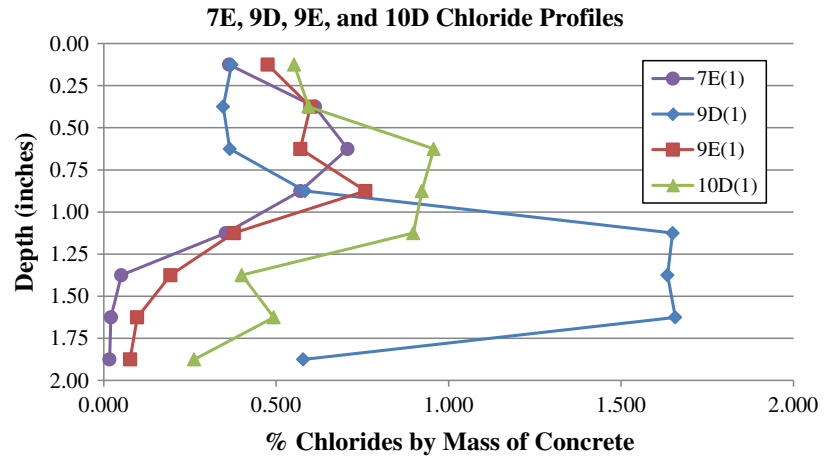

Fig. 8 Chloride profiles for Locations $7 E(1), 9 D(1), 9 E(1)$, and $10 \mathrm{D}(1)(1 \mathrm{in} .=25.4 \mathrm{~mm})$.

Because of the variation in chloride contents at similar locations (Fig. 9, for example), it was concluded that the chloride penetration in these specimens (Nos. 7, 9, and 10) was not one-dimensional and did not conform to Fick's 2nd Law. The specimens affected contained embedded anodes (EA-A and EA-B). Higher chloride contents were observed in the vicinity of these sacrificial anodes.

Additional testing was also performed on the specimens containing EA-B to determine where the variation in chlorides occurred. Two samples were taken near the anode and two sets of two samples were taken from concrete outside the "anode grid". The tests revealed that chloride "hot spots" could be found near the anodes. Additionally, corrosion staining on the surface of the specimens was more severe in the vicinity of the anodes.

The additional results from EA-A (Location 7E) and EA-B (Locations 9D, 9E, and 10D), along with the original results, were then averaged to determine the chloride content at each individual location. With these modifications, the average chloride contents were determined (Table 3). Note, the baseline chlorides are included in the results shown.

Figure 10 displays the chloride profiles of the specimens after 6 months of exposure. As expected, the chloride content was highest at the concrete surface and decreased with the distance from the surface. The testing also revealed that the EP-C was most effective in reducing the ingress of chlorides. This was followed by the T-SS and thermal

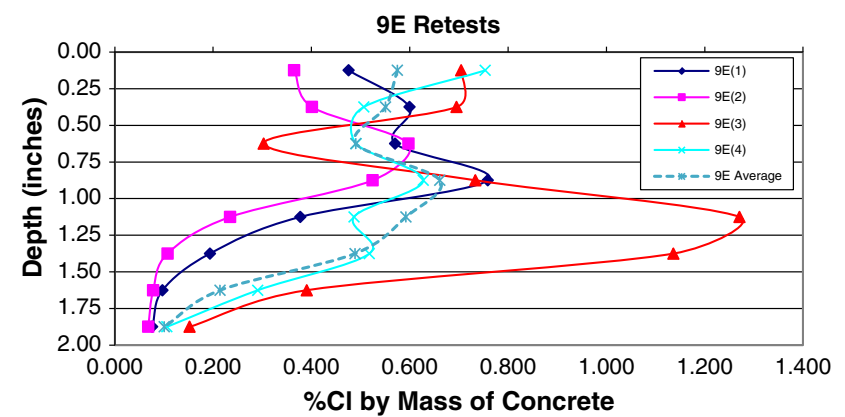

Fig. 9 Chloride contents near Location 9E (1 in. $=25.4 \mathrm{~mm})$.

sprayed zinc with epoxy/polyurethane coating (TSZ w/EPC). Specimens containing the embedded anodes (EA-A and EA-B) displayed markedly different chloride profiles. As discussed earlier, the presence of embedded anodes affected the distribution of chlorides in the horizontal plane.

Using the chloride data, regression and optimization analyses were performed to find the parameters for Fick's 2nd Law of diffusion such that they best-fit the experimental data. The parameters thus calculated were the diffusion coefficients $(D)$ and the surface chloride concentration $\left(C_{0}\right)$.

Prior to regression analysis, the baseline chloride content was subtracted from the values shown in Table 3. By doing so, only the chlorides that penetrated the concrete during exposure were considered.

By utilizing a time of 0.5 years ( 6 months) in the regression analysis, a uniform surface chloride concentration of $0.476 \%$ chlorides by mass of concrete $\left(18.7 \mathrm{lb} / \mathrm{yd}^{3}\right.$ or $11.1 \mathrm{~kg} / \mathrm{m}^{3}$ ) was calculated. An example of the agreement between the actual 6-month chlorides and chloride regression plus base-line chlorides is shown in Fig. 11. Table 4 presents the calculated diffusion coefficients $(D)$ for each specimen and the average $D$ values for each treatment.

It should be noted that a failure occurred at the connection between the thermal spray zinc and reinforcing steel of Specimen No. 2 after $4 \frac{1}{2}$ months. Also, for Specimens No. 7,9 , and 10 , the high $D$ values can be attributed to chloride "hot spots" that are found adjacent to an embedded anode.

Since not all of the specimens followed the classic profile for Fick's 2nd Law (because of hot spots), the estimated 
Table 3 Average acid-soluble chloride content of CoP specimens after 6 months ( 1 in. $=25.4 \mathrm{~mm})$.

\begin{tabular}{|c|c|c|c|c|c|c|c|c|c|}
\hline \multirow[t]{3}{*}{ Depth'specimen } & \multicolumn{9}{|c|}{ Chloride content (\% Chlorides by mass of concrete) } \\
\hline & TSZ & TSZ w/EP-C & EA-A w/A-C & EA-A & EA-B & T-SS & A-C & EP-C & Control \\
\hline & $\# 1$ and $\# 2$ & $\# 3$ and \#4 & $\# 5$ and $\# 6$ & $\# 7$ and \#8 & $\# 9$ and \#10 & $\# 11$ and \#12 & \#13 & \#14 & $\# 15$ and \#16 \\
\hline $0^{n}-1 / 4^{\prime \prime}$ & 0.264 & 0.146 & 0.481 & 0.402 & 0.500 & 0.095 & 0.415 & 0.040 & 0.358 \\
\hline $1 / 4 "-1 / 2 "$ & 0.138 & 0.048 & 0.325 & 0.344 & 0.450 & 0.034 & 0.250 & 0.034 & 0.288 \\
\hline $1 / 22^{m}-3 / 4 m$ & 0.058 & 0.048 & 0.155 & 0.247 & 0.372 & 0.024 & 0.125 & 0.028 & 0.163 \\
\hline $3 / 4^{\prime \prime}-1 ”$ & 0.038 & 0.040 & 0.062 & 0.180 & 0.382 & 0.023 & 0.062 & 0.026 & 0.086 \\
\hline $1 "-1 \frac{1 / 4}{\prime \prime}$ & 0.026 & 0.038 & 0.043 & 0.094 & 0.398 & 0.020 & 0.032 & 0.022 & 0.066 \\
\hline $1 \frac{1 / 4 "-11 / 2 "}{\prime \prime}$ & 0.028 & 0.041 & 0.035 & 0.037 & 0.356 & 0.025 & 0.027 & 0.023 & 0.055 \\
\hline $1 \frac{1 / 2 n}{} " 1^{3 / 4} "$ & 0.026 & 0.026 & 0.024 & 0.021 & 0.238 & 0.029 & 0.038 & 0.019 & 0.045 \\
\hline $1^{3 / 4} "-2 "$ & 0.023 & 0.034 & 0.029 & 0.019 & 0.133 & 0.023 & 0.042 & 0.019 & 0.039 \\
\hline
\end{tabular}

Chloride Content of CoP Specimens

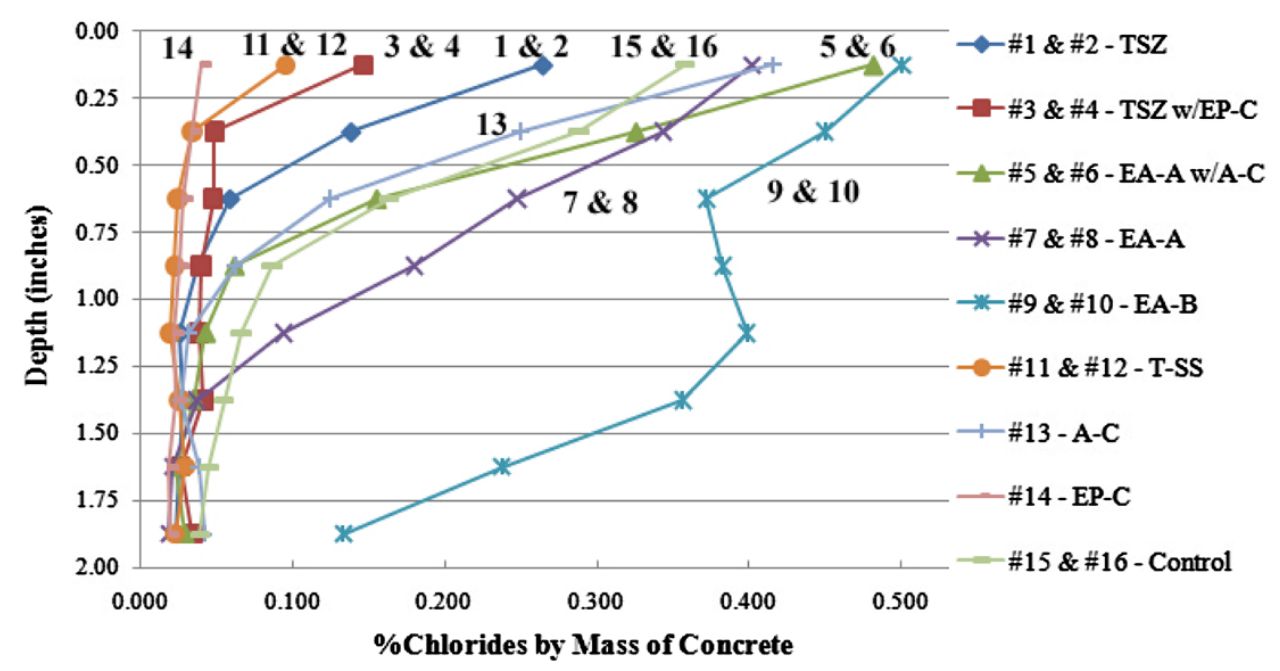

Fig. 10 Chloride content of laboratory specimens $(1 \mathrm{in} .=25.4 \mathrm{~mm})$.

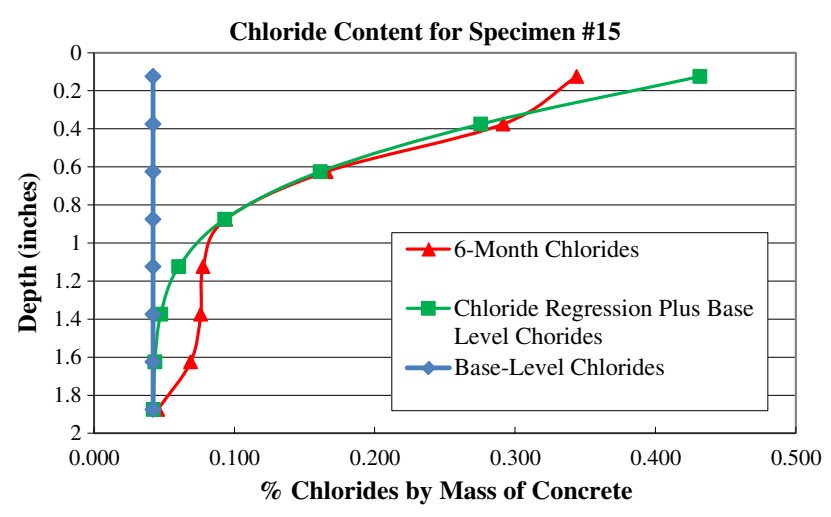

Fig. 11 Agreement of actual and theoretical chlorides for Specimen \#15 (1 in. = $25.4 \mathrm{~mm})$.

diffusion coefficient $(D)$ values could not be used to provide a true comparison. Therefore, the chloride content of the top 1 in. $(2.54 \mathrm{~cm})$ of concrete for all specimens was used as the primary rating criteria for the chlorides at 6 months (Table 5).

Based on these indices of Table 5, it can be concluded that the EP-C, T-SS, and TSZ w/EP-C were most effective in reducing the ingress of chlorides. In contrast, EA-A and EA-B were least effective in reducing chloride ingress. From the results, it appears that the embedded anodes actually attracted chlorides to their vicinity. As the embedded anodes release electrons, they become positively charged and thus would attract the negatively-charged chloride ions to their vicinity.

\subsection{Surface Staining and Corrosion of Reinforcement}

To provide a quantitative measure of the condition of the specimens after exposure to accelerated corrosion testing, a visual examination of the rust staining on the concrete surface (Fig. 12) and exposed reinforcing steel (Fig. 13) was performed so that a numerical rating could be assigned to each of the specimens.

Based on a rating scale of $0-4$, with 0 being the best condition and 4 being the worst condition, rust staining on the surface of the specimens and the level of section loss in the reinforcing steel were each evaluated. The two ratings were then added together to determine a combined rating.

In Table 6, Bar A denotes the top mat reinforcing steel on the west end of the specimens while Bar E denotes the reinforcing steel on the east end of the specimens. The rating scale for staining was based purely on visual examination; 
Table 4 Calculated average chloride diffusion coefficients for specimens after 6 months $(1 \mathrm{in} .=25.4 \mathrm{~mm})$.

\begin{tabular}{|c|c|c|c|}
\hline Specimen \# & Treatment & $\mathrm{C}_{0}(\% \mathrm{Cl})$ & $\mathrm{D}_{\text {Treatment }}\left(\right.$ in $^{2} /$ year $)$ \\
\hline 1 and 2 & TSZ & \multirow[t]{9}{*}{0.476} & 0.054 \\
\hline 3 and 4 & TSZ w/EP-C & & 0.011 \\
\hline 5 and 6 & EA-A w/A-C & & 0.320 \\
\hline 7 and 8 & EA-A & & 0.586 \\
\hline 9 and 10 & EA-B & & 4.831 \\
\hline 11 and 12 & T-SS & & 0.002 \\
\hline 13 & $\mathrm{~A}-\mathrm{C}$ & & 0.215 \\
\hline 14 & EP-C & & 0.000 \\
\hline 15 and 16 & Control & & 0.282 \\
\hline
\end{tabular}

Table 5 Top 1 in. chlorides for CoP specimens after 6 months ( 1 in. $=25.4 \mathrm{~mm}$ ).

\begin{tabular}{c|c|c|c}
\hline Specimen $\#$ & Treatment & Average $\% \mathrm{Cl}^{-}$in top 1-in. & $\begin{array}{c}\text { Average index for } \% \mathrm{Cl}^{-} \text {in top } \\
1 \text {-in. }\end{array}$ \\
\hline \hline 1 and 2 & TSZ & 0.124 & 0.87 \\
\hline 3 and 4 & TSZ w/EP-C & 0.071 & 0.36 \\
\hline 5 and 6 & EA-A w/A-C & 0.256 & 2.10 \\
\hline 7 and 8 & EA-A & 0.293 & 2.44 \\
\hline 9 and 10 & EA-B & 0.426 & 3.69 \\
\hline 11 and 12 & T-SS & 0.044 & 0.11 \\
\hline 13 & A-C & 0.213 & 1.70 \\
\hline 14 & EP-C & 0.032 & 0.00 \\
\hline
\end{tabular}

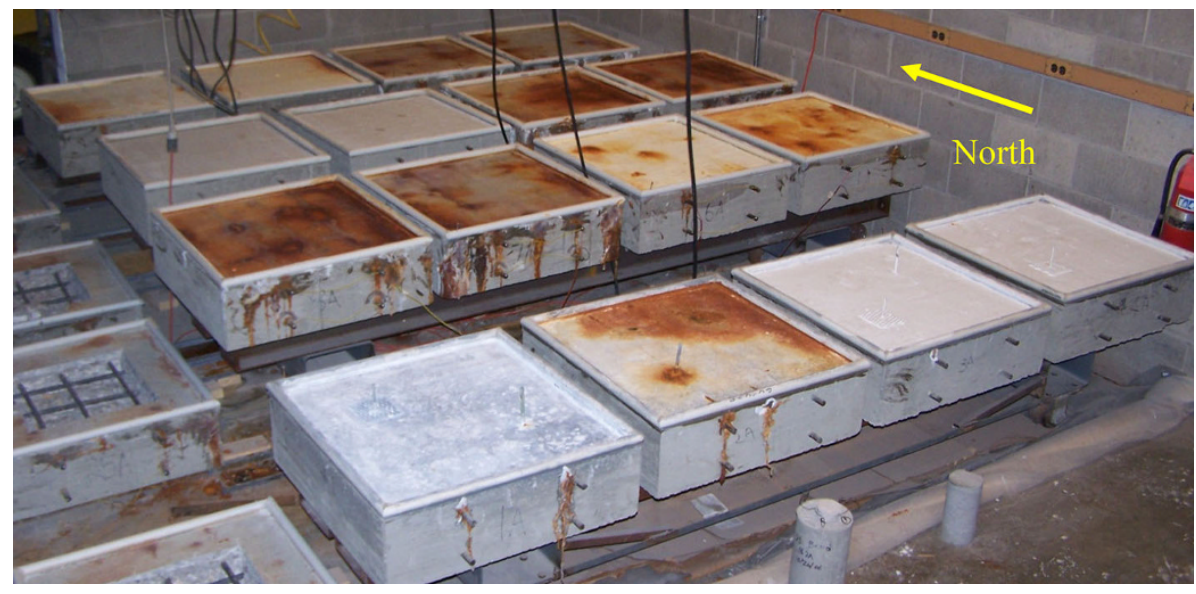

Fig. 12 Surface staining on laboratory specimens after 6 months.

the more severe the staining, the higher the rating. The rating scale for the condition of the exposed reinforcing steel was based on the loss of ribs. If no corrosion by-products were present, a rating of 0 was given (Fig. 14). If it appeared that all of the ribs were lost, a rating of 4 was given (Fig. 15).

Based on the rating criteria of Table 6, T-SS (No. 11 and 12) and TSZ w/EP-C (No. 3 and 4) performed the best. The specimens with the embedded anodes (No. 7-No. 10) did not perform better than the control (No. 15-No. 16).

\subsection{Crack Mapping}

Crack mapping as performed with a crack map gauge prior to the application electrical current and ponding for an initial condition assessment of each specimen. There were some 


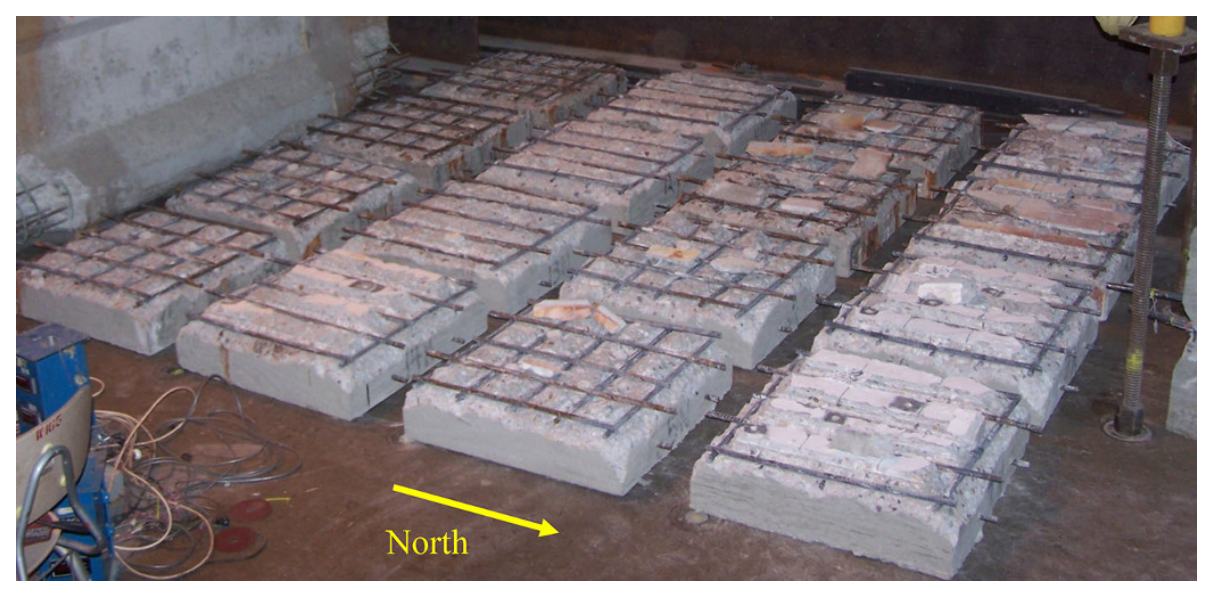

Fig. 13 Discected laboratory specimens.

Table 6 Rating of concrete staining and reinforcing steel after 6 months.

\begin{tabular}{|c|c|c|c|c|c|c|c|c|c|}
\hline \multirow[t]{2}{*}{ Specimen \# } & \multirow[t]{2}{*}{ Treatment } & \multicolumn{5}{|c|}{ Individual bar } & \multirow[t]{2}{*}{$\mathrm{Bar}_{\mathrm{Avg}}$. } & \multirow{2}{*}{$\begin{array}{l}\text { Surface } \\
\text { staining }\end{array}$} & \multirow{2}{*}{$\begin{array}{c}\text { Average } \\
\text { combined } \\
\text { rating }\end{array}$} \\
\hline & & A & B & $\mathrm{C}$ & $\mathrm{D}$ & $\mathrm{E}$ & & & \\
\hline 1 and 2 & TSSZ & 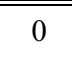 & 2.5 & 2.5 & 2.5 & 0.5 & 1.6 & 2 & $3.6^{\mathrm{a}}$ \\
\hline 3 and 4 & TSZ w/EP-C & 0.5 & 2 & 0.5 & 1 & 0 & 0.8 & 0 & 0.8 \\
\hline 5 and 6 & EA-A w/A-C & 3.5 & 3 & 3 & 2.5 & 2.5 & 2.9 & 3.5 & 6.4 \\
\hline 7 and 8 & EA-A & 3.5 & 4 & 3.5 & 4 & 3.5 & 3.7 & 4 & 7.7 \\
\hline 9 and 10 & EA-B & 4 & 4 & 4 & 4 & 4 & 4.0 & 4 & 8.0 \\
\hline 11 and 12 & T-SS & 0 & 0.5 & 0.5 & 0.5 & 0.5 & 0.4 & 0 & 0.4 \\
\hline 13 & A-C & 4 & 2 & 2 & 2 & 2 & 2.4 & 3 & 5.4 \\
\hline 14 & EP-C & 4 & 1 & 1 & 2 & 1 & 1.8 & 2 & 3.8 \\
\hline 15 and 16 & Control & 4 & 4 & 4 & 4 & 4 & 4.0 & 4 & 8.0 \\
\hline
\end{tabular}

${ }^{a}$ The connection between the thermal sprayed zinc and reinforcing steel of Specimen $\# 2$ failed after $41 / 2$ months of testing

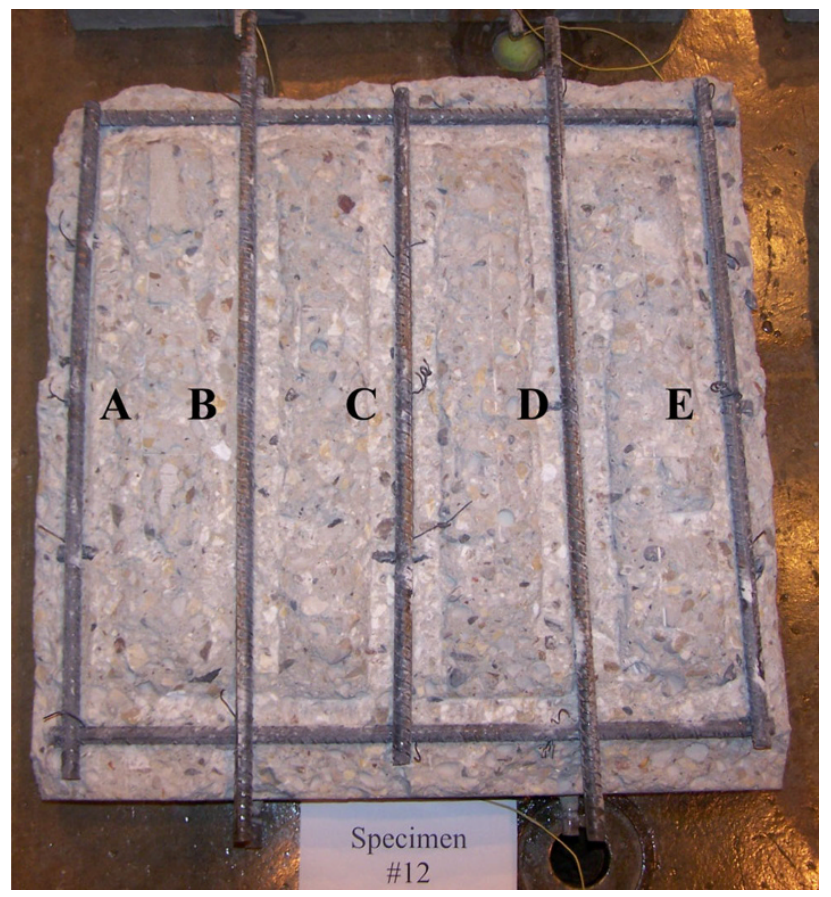

Fig. 14 Condition of Specimen \#12 (T-SS).

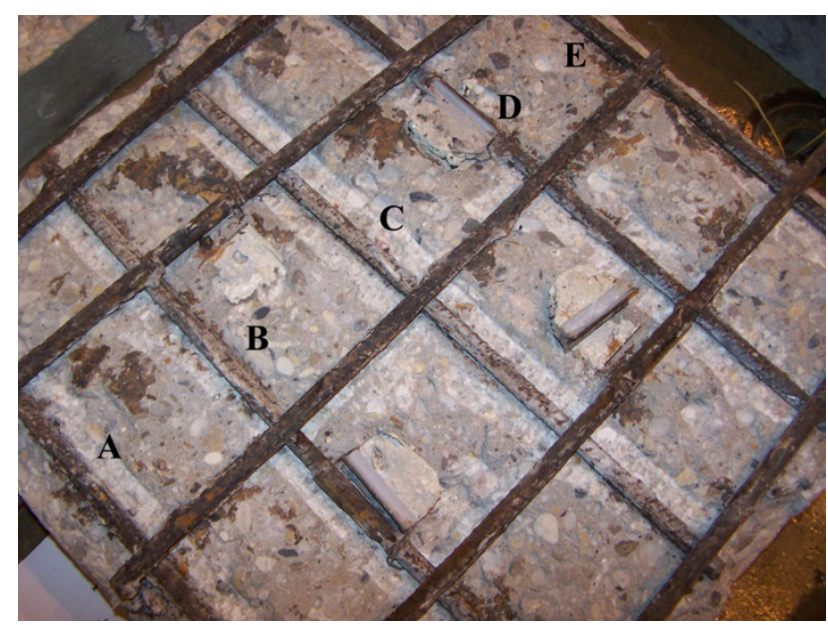

Fig. 15 Condition of Specimen \#9 (EA-B).

hairline cracks present in a few of the specimens at the onset of testing ( 0 month). However, the cracks were small, ranging from 0.002 to 0.005 in. (0.05 to $0.13 \mathrm{~mm})$, except for TSZ (2) which had one crack of $0.010 \mathrm{in}$. $(0.25 \mathrm{~mm})$. Additional crack mapping was performed at 3 months and at 

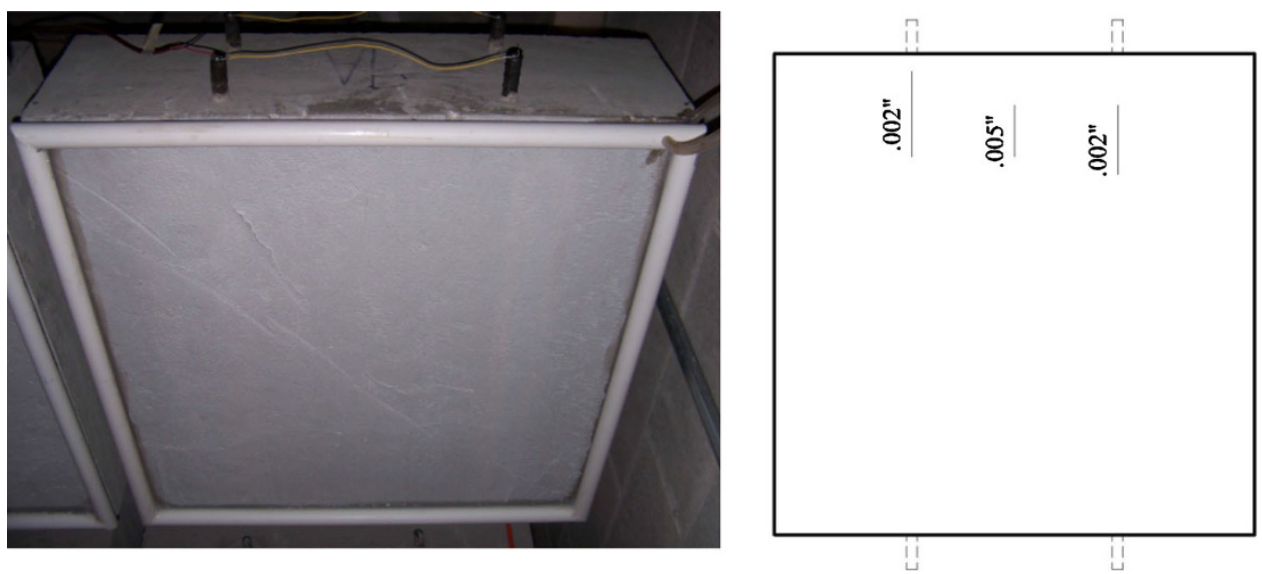

Fig. 16 Condition and crack mapping of Specimen \#9 (EA-B) at 0 month.
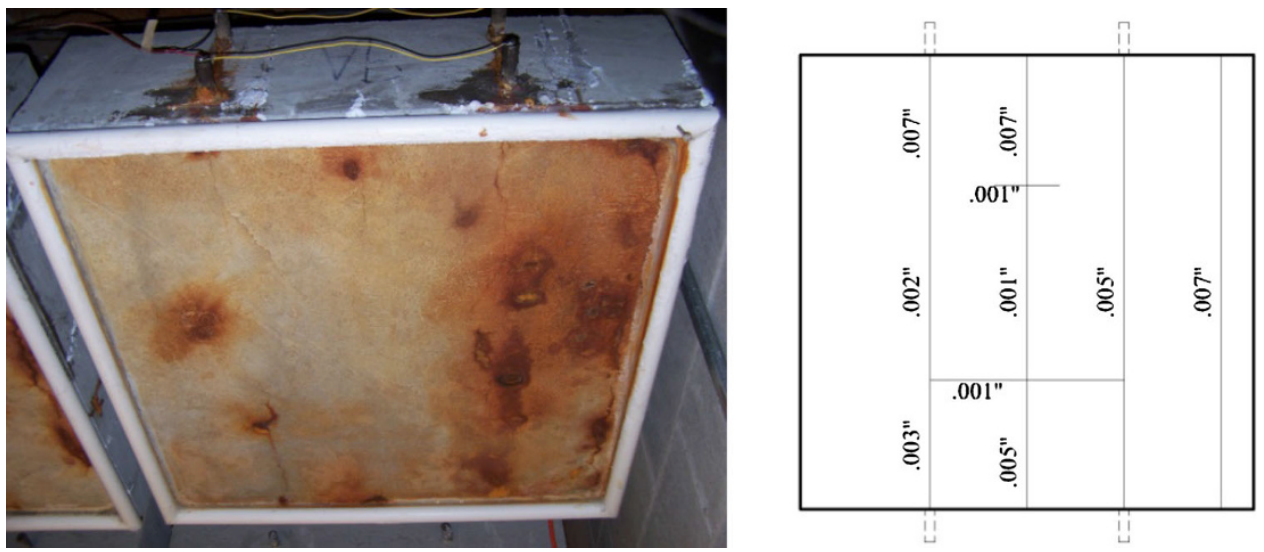

Fig. 17 Condition and crack mapping of Specimen \#9 (EA-B) at 3 months.

Table 7 Average half-cell potential readings of uncoated specimens after 3 months.

\begin{tabular}{c|c|c|c}
\hline Specimen $\#$ & Treatment & Treatment $_{\text {Avg }}(\mathrm{mV})$ & Treatment $_{\text {StDev }}(\mathrm{mV})$ \\
\hline \hline 7 and 8 & EA-A & 608.9 & 26.9 \\
\hline 9 and 10 & EA-B & 637.5 & 21.1 \\
\hline 11 and 12 & T-SS & 354.6 & 22.1 \\
\hline 15 and 16 & Control & 604.4 & 36.2 \\
\hline
\end{tabular}

the end of the experimental program ( 6 months). The most pronounced difference in cracking between 0 and 3 months occurred in the specimens containing embedded anodes (Figs. 16 and 17).

\subsection{Half-Cell Potential}

Half-cell measurements utilizing a copper-copper sulfate electrode were obtained for each of the concrete specimens that did not contain coatings. Prior to measurement during the dry cycle, the accelerated corrosion system was turned off for a day and the slabs were moistened with tap-water. Readings were made after 3 months (Table 7) and 6 months (Table 8). Since the readings were generally uniform, contour plots were not made. Additionally, positive values were obtained since the polarity of experimental setup is reversed from the standard method.

Based on half-cell potential readings from Table 7, there is a strong probability that corrosion was occurring in the specimens containing EA-A and EA-B, as well as the Control specimens, after 3 months of exposure. However, the T-SS specimens were at the threshold of unknown probability of corrosion after 3 months of exposure.

The 6-month half-cell readings for the specimens containing EA-A and EA-B, as well as the Control, indicated that corrosion was occurring (Table 8 ). However, the readings for the T-SS specimens indicated that corrosion was not occurring.

\section{Discussion}

In the previous sections, the rating criterion for the specimens was presented. Since half-cell potential readings were not performed on all of the specimens, they are not included in Table 9, which summarizes the results of tests for all specimens. 
Table 8 Average half-cell potential readings of uncoated specimens after 6 months.

\begin{tabular}{c|c|c|c}
\hline Specimen $\#$ & Treatment & Treatment $_{\text {Avg }}(\mathrm{mV})$ & Treatment $_{\text {StDev }}(\mathrm{mV})$ \\
\hline \hline 7 and 8 & EA-A & 579.1 & 17.9 \\
\hline 9 and 10 & EA-B & 582.4 & 28.1 \\
\hline 11 and 12 & T-SS & 186.7 & 4.1 \\
\hline 15 and 16 & Control & 594.5 & 29.7 \\
\hline
\end{tabular}

Table 9 Condition summary of specimens after 6 months.

\begin{tabular}{|c|c|c|c|c|c|}
\hline \multirow[t]{2}{*}{ Specimen \# } & \multirow[t]{2}{*}{ Treatment } & \multicolumn{3}{|c|}{ 6-month indices } & \multirow[t]{2}{*}{ Total (out of 16) } \\
\hline & & Steel loss (out of 4) & $\begin{array}{c}\text { Chloride content (out } \\
\text { of } 4 \text { ) }\end{array}$ & $\begin{array}{c}\text { Rebar corrosion and } \\
\text { staining (out of } 8 \text { ) } \\
\end{array}$ & \\
\hline 1 and 2 & TSZ & 1.1 & 0.9 & 3.6 & 5.5 \\
\hline 3 and 4 & TSZ w/EP-C & 0.3 & 0.4 & 0.8 & 1.5 \\
\hline 5 and 6 & EA-A w/A-C & 1.2 & 2.1 & 6.4 & 9.7 \\
\hline 7 and 8 & EA-A & 1.9 & 2.5 & 7.7 & 12.1 \\
\hline 9 and 10 & EA-B & 3.6 & 3.7 & 8.0 & 15.3 \\
\hline 11 and 12 & T-SS & 0.0 & 0.1 & 0.4 & 0.5 \\
\hline 13 & A-C & 0.5 & 1.7 & 2.0 & 4.2 \\
\hline 14 & EP-C & 0.3 & 0.0 & 2.0 & 2.3 \\
\hline 15 and 16 & Control & 2.0 & 1.8 & 8.0 & 11.8 \\
\hline
\end{tabular}

Based on the stated criteria, the T-SS and TSZ w/EP-C treatments offered the most effective means of preventing corrosion from initiating. Treatments that coated or sealed the concrete surface prior to exposure offered the most protection. As stated earlier, the connection for Specimen No. 2 had failed after $4 \frac{1}{2}$ months; therefore, it is anticipated that better performance, likely similar to Specimen No. 1, may have been observed if a failure of the connection had not occurred.

Specimens No. 7 thru No. 10 (those containing embedded anodes) had less favorable total ratings than the control specimens. The embedded anodes appear to attract more chlorides to their vicinity which created variable chloride concentrations and non-uniform chloride penetrations in the laboratory specimens containing the embedded anodes.

It is anticipated that the negatively charged chloride ions will be attracted to the vicinity of the zinc anodes when the anode is working (i.e. releasing electrons and becoming positively charged). When the anode is consumed, zones of varying chloride concentrations would remain along the bar, thus creating varying corrosion potentials along the bar.

When comparing the EA-A and EA-A w/A-C, the addition of the acrylic coating improves the performance. However, the A-C alone was more effective in preventing corrosion than the EA-A or EA-A w/A-C laboratory specimens.

\section{Conclusions}

Based on the observations of the laboratory specimens subjected to an accelerated corrosion regime, the following conclusions are made:
1. The T-SS and thermal sprayed zinc with epoxy/ polyurethane coating (TSZ w/EP-C) were found to be the most effective in preventing the initiation of corrosion.

a. Because of the additional effort required for installing the TSZ w/EP-C, the T-SS appears to be the simplest choice in preventing the initiation of corrosion.

b. The EP-C alone offered significant protection as well.

c. Although a connection failed in one of the TSZ specimens, the method appeared to be effective when working properly. The potential for a damaged connection may also exist in the field and steps should be taken to prevent it.

2. The embedded anodes (both EA-A and EA-B) attracted more chlorides to their vicinity and created variable chloride concentrations and non-uniform chloride penetrations in the horizontal plane.

3. The use of coatings in conjunction with the embedded anodes was moderately effective; however, the acrylic coating (A-C) alone was more effective than the embedded anode with acrylic coating (EA-A w/A-C).

\section{Acknowledgments}

The authors wish to express their gratitude and sincere appreciation to the Wisconsin Highway Research Program for funding this effort. The project team would also like to 
thank Ambassador Steel of Waukesha, Wisconsin for donating materials; Masonry Restoration, Inc. of Milwaukee, Wisconsin, for lending their demolition equipment; Aaron Coenen, John Condon, Chin Wei-Lee, Cory Schultz, and Rahim Reshadi for assisting with the placement of concrete; and Dr. Tracy Pritzl for her assistance with chloride testing.

\section{Open Access}

This article is distributed under the terms of the Creative Commons Attribution License which permits any use, distribution, and reproduction in any medium, provided the original author(s) and the source are credited.

\section{References}

Abosrra, L., Ashour, A. F., \& Youseffi, M. (2011). Corrosion of steel reinforcement in concrete of different compressive strengths. Construction and Building Materials, 25, 3915-3925.

American Concrete Institute Committee 222. (2001). ACI 222R01: Protection of metals in concrete against corrosion. American Concrete Institute, Committee 222 Report.

Austin, S. A., Lyons, R., \& Ing, M. J. (2004). Electrochemical behavior of steel-reinforced concrete during accelerated corrosion testing. Corrosion, 60(2), 203-212.

Ball, J. C. \& Whitmore, D. W. (2003). Corrosion mitigation systems for concrete structures. Concrete Repair Bulletin, 6-11. http://www.icri.org/publications/2003/PDFs/julyaug03/ CRBJulyAug03_Ball.pdf.

Brown, M. C. (1999). Assessment of commercial corrosion inhibiting admixtures for reinforced concrete (p. 163). Blacksburg: s.n. ETD-122199-104756.

Daily, S. F. \& Green, W. K. (2005). Galvanic cathodic protection of reinforced and prestressed concrete structures using CORRSPRAY - a thermally sprayed aluminum alloy (p. 8). s.1.: Corrpro Companies, Inc. Technical Paper 51.

El Maaddawy, T. A., \& Soudki, K. A. (2003). Effectiveness of impressed current technique to simulate corrosion of steel reinforcement in concrete. Journal of Materials in Civil Engineering, 15, 41-47.
El-Reedy, M. A. (2008). Steel-reinforced concrete structures: Assessment and repair of corrosion (p. 216). Boca Raton: Taylor \& Francis Group. ISBN 978-1-4200-5430-9.

Emmons, P. H. (1993). Concrete repair and maintenance illustrated (p. 295). Kingston, MA: RS Means. ISBN 9-780876-292860.

Federal Highway Administration. (1998). Corrosion protection: Concrete bridges. Report No. FHWA-RD-98-088, Federal Highway Administration, Turner-Fairbank Highway Research Center. [Online] http://www.tfhrc.gov/structur/ corros/corros.htm. Accessed on 2008.

Germann Instruments. (2006). RCT \& RCTW. Summary of Germann Instruments. [Online]. Retrieved November 29, 2008 from www.germann.org/Pages/Products/RCT\%20og\% 20RCTW/RCT\%20og\%20RCTW.htm.

Holcomb, G. R., Covino Jr, B. S., Cramer, S. D., Russell, J. H., Bullard, S.J., \& Collins, W. K. (2002). Humectants to augment current from metallized zinc cathodic protection systems on concrete (p. 122). Oregon Department of Transportation, Salem, OR, Report FHWA-OR-RD-03-08.

Michel, A., et al. (2011). Monitoring reinforcement corrosion and corrosion induced cracking using non-destructive X-ray attenuation measurements. Cement and Concrete Research, 41, 1085-1094.

Mullard, A., \& Stewart, M. G. (2011). Corrosion-induced cover cracking: New test data and predictive models. $A C I$ Structural Journal, 108(1), 71-79.

Ray, I., Parish, G., Davalos, J., \& Chen, A. (2011). Effect of concrete substrate repair methods for beams aged by accelerated corrosion and strengthened with CFRP. Journal of Aerospace Engineering, 24(2), 227-239.

Tabatabai, H., Ghorbanpoor, A. \& Turnquist-Nass, A. (2005). Rehabilitation techniques for concrete bridges. Wisconsin Department of Transportation Report for project No. 0092-01-06, p. 309.

Tabatabai, H., Pritzl, M. D. \& Ghorbanpoor, A. (2009). Evaluation of select methods of corrosion prevention, corrosion control, and repair in reinforced concrete bridges (p. 343). Madison, WI: Wisconsin Highway Research Program, Report No. WHRP 09-04.

Weyers, R. E., Chamberlin, W. P., Hoffman, P., \& Cady, P. D. (1994). Concrete bridge protection and rehabilitation: Chemical and physical techniques-service life estimates (p. 357). Strategic Highway Research Program-National Research Council, Washington, DC, Report SHRP-S-668. 